Revista Iberoamericana, Vol. LXXX, Núm. 247, Abril-Junio 2014, 553-570

\title{
LAS ILUSIONES PERDIDAS: NARRAR LA VIOLENCIA. ACERCAMIENTOS A LA OBRA DE HORACIO CASTELLANOS MOYA
}

\author{
POR \\ María del Pilar Vila \\ Universidad Nacional del Comahue
}

Llevamos encima la tara de la dimensión territorial, No somos continentales, ni siquiera antillanos: somos simplemente insulares que es como decir insulados en casa estrecha.

Antonio S. Pedreira, Insularismo

La ubicación geopolítica de los países que forman parte de Centroamérica le permitió al istmo ser un punto de atracción tanto para los conquistadores como para los viajeros que, con distintos propósitos llegaron a la zona. Una región vista como paradisíaca, pródiga en minerales y vegetales, conformada por una población que rápidamente fue diezmada y un enclave que permite vínculos notables con el resto del mundo, son algunas de las particularidades de este territorio delineado como un espacio apetecido pero también, en gran medida, estereotipado.

La delimitación del territorio representa un problema que tiene distintas aristas. Por un lado, acordar acerca de cuáles son los países que lo integran, por otro qué es lo que los relaciona para constituir lo que se conoce como Centroamérica. Este último aspecto se liga con la idea de que existen puntos de vinculación: la lengua, la historia, los avatares políticos, las guerras internas, la cultura, las etnias. Esta rápida enumeración deja a la vista la imposibilidad de elegir uno o más aspectos como elementos que permitan inferir un cierto matiz definitorio de la región. La heterogeneidad y diversidad de enfoques que implica la consideración de cualquiera de ellos revela la complejidad que entraña el concepto en cuestión y, sobre todo, la fragilidad que conllevan las posibles opciones.

Dante Liano, en un meduloso ensayo, sostiene que pretender delimitar este territorio es "una arbitrariedad [porque] toda Centroamérica es una arbitrariedad” (51), afirmación basada en el análisis de las distintas categorías con las que se podría definir al istmo y a las que habría que agregar los desplazamientos producidos a partir de los ochenta que marcaron fuertes “procesos de desterritorialización” (Cortez, Mapas 144). Más allá de compartir las reflexiones de Liano, entiendo que los impedimentos para señalar con precisión de qué hablamos cuando hablamos de Centroamérica, no distan demasiado 
de los análisis de los latinoamericanistas cuando se trata de delimitar Nuestra América. Las recordadas palabras de José Luis Martínez - unidad en la diversidad-vienen una vez más en auxilio para poder pensar en una región que reúne historias, lenguas, culturas diferentes y, al mismo tiempo, comparte proyectos y fracasos, un territorio en el que las aproximaciones y los alejamientos son una muestra de la precariedad y arbitrariedad de las clasificaciones

No obstante ello, estas cuestiones son discutidas y analizadas en la actualidad por quienes, además, procuran cancelar la marginalidad de la región partiendo de la idea de que es preciso revisar y reconsiderar la historia política y cultural focalizando su atención, de modo especial, en el discurso literario. Son un ejemplo los aportes provenientes de Werner Mackenbach, Beatriz Cortez, Alexandra Ortiz Wallner, Damaris Serrano Guerra, Magda Zavala y Seidy Araya, entre otros. La revista de estudios literarios y culturales Istmo es, por otra parte, un punto de referencia ineludible para tener en cuenta los estudios actuales de un área geográfica-cultural compleja y heterogénea que reclama atención.

La literatura de la región, en particular la producida en los años noventa evidencia un desplazamiento en las temáticas puesto que se trata de mostrar cómo los acontecimientos políticos, sociales, económicos fueron marcados por la violencia, en sus más variadas representaciones, constituyendo una marca sustantiva de la sociedad centroamericana. Se trata de un giro fundado en el hecho de que los cambios operados en el campo político y social impregnaron el horizonte literario centroamericano y generaron obras ficcionales y ensayísticas que abandonaron los paradigmas estéticos imperantes en la segunda mitad del siglo xx y direccionaron sus obras hacia temáticas relacionadas a ficcionalizar un tiempo de desesperanza y violencia. ${ }^{1}$

Algunos autores señalan que se trata de una etapa marcada por la caída del boom en tanto que otros hablan del surgimiento de un mini-boom (Arias, Gestos). Lo cierto es que se asiste a la emergencia de una narrativa caracterizada por "el desencanto y desilusión de la democracia neoliberal [época] que con cantos de sirena atrajo a las masas agotadas tras el esfuerzo titánico de treinta años de tenaz lucha. Ella también está siendo madre de textos de extraordinario valor documental y literario" (Galich) y a la que con frecuencia se la identifica como la "narrativa de posguerra".

De modo que "narrativa de posguerra", "de violencia" o "estética del cinismo" -conceptos que han generado intercambios teóricos al considerar la pertinencia de su denominación (Cortez, Estética 23-24)- son, desde mi perspectiva, expresiones de una

\footnotetext{
1 Me refiero, por ejemplo, a las obras de Sergio Ramírez (Nicaragua), Carlos Cortés (Costa Rica), Franz Galich (Guatemala-Nicaragua), Rodrigo Rey Rosa (Guatemala), Juan Pedro Gutiérrez (Cuba), entre otros. No puedo dejar de considerar en este contexto, ciertos ‘aires de familia' con la obra del colombiano Fernando Vallejo porque hay una notoria vinculación en el modo en que aborda temáticas similares con una estética también similar. Por caso, el tratamiento de la violencia sin vinculaciones de índole política como se observa en La virgen de los sicarios.
}

Revista Iberoamericana, Vol. LXXX, Núm. 247, Abril-Junio 2014,
ISSN 2154-4794 (Electrónico) 
escritura que disecciona los distintos estamentos sociales para dejar a la vista la ausencia de emblemas o de modelos y que hacen visible la crisis de identidad cultural, aspecto presente en la narrativa de gran parte de los escritores centroamericanos (Mackenbach, "Representaciones”). En todo caso, esas caracterizaciones definen lo que acertadamente Cortez llamó "sensibilidad de posguerra”, construcción que indica "un momento de desencanto, de pérdida de liderazgo y de pérdida de fe en los proyectos utópicos que formaban parte del momento revolucionario en Nicaragua, El Salvador y Guatemala, así como en el resto de los países centroamericanos” entendiendo, además, que se trata de un momento que se contrapone con "la sensibilidad utópica y esperanzadora" que acompañó los procesos revolucionarios (Estética 25).

En ese contexto, los escritores asumen "contrarrepresentarse como un sujeto marginal” (Arias, "Descolonizando” 76) y para hacerlo apelan a un discurso en el que la nación, la cultura, la lengua y los actores sociales se entroncan con la decadencia y la derrota. Demuelen esos conceptos aún sabiendo que esta decisión puede llevarlos a ser marginados, pero no vacilan en destacar que la violencia es consustancial a sus respectivos países. Algunos señalan la íntima vinculación de esta idea con la pérdida de expectativas y cómo "la frustración de la transición democrática” ahondó la desilusión, que produjo el hecho de que la sociedad no vivió o conoció la ansiada transformación prometida, cuestión que se expresa en una literatura atravesada por el fracaso y la tragedia (Menjívar).

La narrativa de los noventa da paso a una etapa de la historia de América Central que "podría casi fecharse desde la derrota electoral de los sandinistas en febrero de ese mismo año [los noventa]. El fin del guerrillerismo y del sueño utópico de la revolución cambia el marco simbólico del ser centroamericano y redefine prioridades, identidades y proyectos culturales” (Arias, “Descolonizando” 73). Precisamente el desplazamiento de estos últimos conceptos es el que marca esta producción literaria y propicia un corrimiento del eje de las inquietudes de los escritores manifestado en distintas representaciones de la violencia, en particular en aquellas que no sólo atienden a cuestiones estrictamente vinculadas con aspectos políticos o ideológicos, sino que más bien se centran en la ciudad o el poder. Es una escritura que pone de relieve la relación entre literatura y violencia de allí que maltratos, exilio, desamparo, carencia y desesperanza constituyen aspectos que la impregnan. Dante Liano denomina a estas obras "textos de violencia oblicua” (Liano en Mackenbach, “Entre política” y funda este concepto en la idea de que se las ha despojado de su contenido político-ideológico al no tener ningún tipo de justificación ético-moral. Prefiero considerar que precisamente por estar despojado de estos contenidos, la explicitación directa de la violencia adquiere una dimensión que, lejos de ser oblicua, ocupa el centro de la escena puesto que al ingresar en la vida del hombre en toda su dimensión, configura un punto de quiebre en el horizonte lector. Es un tiempo que evidencia los fracasos revolucionarios y que muestra la debilidad de las

\footnotetext{
Revista Iberoamericana, Vol. LXXX, Núm. 247, Abril-Junio 2014, 553-570 ISSN 0034-9631 (Impreso) ISSN 2154-4794 (Electrónico)
} 
utopías revolucionarias, a partir de un registro de los resultados que dejaron las guerras, el exilio y la persecución.

En algunas novelas se observa que la ficcionalización de vidas marginales se entronca con otra manera de enfocar temas centrales como lo son la identidad, la nacionalidad, la historia y la cultura, cuestiones por cierto significativas para entender ese territorio que pugna por cancelar el mundo colonial (Ortiz Wallner, "Ensayar una historia”). Estos aspectos, unidos al tratamiento del tema de la relación entre memoria y olvido, se visualizan en una escritura que, al margen del género elegido para expresarlo y del momento histórico en el cual aparece, es "una discursividad que replantea la construcción de la nacionalidad y del sujeto centroamericano" (Arias 274). Se deja a la vista, en definitiva, la complejidad de un territorio convulso, conflictivo y difícilmente delimitable, territorio largamente sometido y que procuró resistir con persistencia la dominación y el colonialismo. Varias razones concurren para que esto sea así: económicas, políticas, sociales, lingüísticas, religiosas, étnicas. Paraíso deseado y paraíso perdido reunió la explotación, la aventura, y la violencia.

Se trata, además, de una región en la que los aspectos identitarios constituyeron el eje de las preocupaciones históricas, sociales, políticas y artísticas. Una cuestión no menos significativa -que fue y es uno de los ejes de análisis y, en algunos momentos un aspecto axial- es la heterogeneidad étnica. Los distintos discursos articulados en torno al tema dan cuenta de ello, en particular aquellos que eligen el género testimonial para hacerlo. Entre quienes abordan estas cuestiones, la crítica coincide en señalar algunas novelas de Luis de Lión, Claribel Alegría y Tatiana Lobo y los relatos testimoniales de Omar Cabezas, Rigoberta Menchú y Mario Payeras. ${ }^{2}$ Frente a este panorama no es de extrañar que la violencia forme parte del contexto de un territorio sometido a tensiones internas y externas, partícipe de proyectos políticos que se fueron diluyendo y dejaron una sociedad desencantada ante la pérdida de las utopías. Por cierto estas ilusiones perdidas emergieron, tal vez de modo irregular o con tiempos diferentes, en gran parte de todo el territorio latinoamericano. Es también un momento en el que asoman escritores que se apartan de los proyectos literarios tradicionales y de los discursos revolucionarios. ${ }^{3}$ Tampoco sostendrán la imagen mágica del continente puesto que desvían sus miradas a otras zonas para revisar la construcción que se ha hecho de sus respectivos países, interpelando y resignificando acontecimientos políticos, sociales y culturales. Apelan a la construcción de otra visión de sus países para hacer, mayormente, de la relación literatura y violencia el eje más notable de sus obras.

2 Ver Erick Aguirre Aragón, "Control discursivo y alteridad en el testimonio centroamericano. Cinco modelos representativos".

3 En este sentido hay un alejamiento, por ejemplo, de lo que sostenía Sergio Ramírez al reclamar una cultura íntimamente vinculada con el proceso revolucionario de su país. Cfr. Balcanes y volcanes y otros ensayos y trabajos, 187.

Revista Iberoamericana, Vol. LXXX, Núm. 247, Abril-Junio 2014,
ISSN 0034-9631 (Impreso) 
Por otra parte, en el camino iniciado para definir Centroamérica, emerge la necesidad de pensar una historia de la literatura centroamericana, lo que implica diseñar un lugar simbólico donde reunir obras incrustadas en un territorio que desplace algunas fronteras geopolíticas y pueda pensarlo como una única nación ante la evidencia de que categorías como períodos o generaciones resulta insuficientes.

Franz Galich expresa la voluntad de escribir una historia a partir de preguntarse si “existimos, nosotros, los que vivimos en esta porción de tierra ístmica y sísmica” dado que entiende que son precisamente los escritores quienes pueden dar respuesta a ese interrogante. En gran medida trata de mapear la región cuando afirma que

Una cosa sí parece quedar clara, por lo menos para nosotros: actualmente Centroamérica la conforman siete países, a saber: Guatemala, Belice, El Salvador, Honduras, Nicaragua, Costa Rica y Panamá, incluyendo, por supuesto, todas las regiones y áreas que presentan conflictos étnicos. Pienso en la costa Caribe nicaragüense que reclama su autonomía, los Garífunas de Honduras, los Cunas de Panamá, etc.

Otros proyectos son el resultado de investigaciones universitarias de distintos países centroamericanos, como es el caso de Hacia una historia de las literaturas Centroamericanas. ${ }^{4}$ En estos trabajos quedan a la vista las dificultades que importa la delimitación del territorio porque no es posible recortar los bordes de manera contundente. Arcadio Díaz Quiñones destaca que la mayor dificultad radica en la imprecisión de los límites políticos del Caribe y en haber asociado a la región con la idea de "la isla perdida", cuestión que contribuyó a congelar la imagen del istmo con la de "los caníbales" (20-21). Otro aspecto que entiendo colabora con la indefinición es que se observa que, con frecuencia, los escritores se identifican con una doble nacionalidad. Más allá de ser un punto de referencia para evidenciar la complejidad, acuerdo que es un modo de impulsar el "intercambio cultural y literario entre nuestros pueblos que no conocen fronteras ni diferendos territoriales” y que aspiran a una convivencia sostenida por la palabra (Mackenbach, "Representaciones”; Ruiz Puga).

Buena parte de la producción literaria de los noventa articula literatura y política con un tiempo histórico-político de transición: la/s revolución/es, los movimientos guerrilleros, los Acuerdos de Paz, los procesos de democratización, nueva narrativa y nuevos espacios son presencias constantes. Entre quienes abordan estas cuestiones, se puede mencionar, a Gioconda Belli, Sergio Ramírez, Rodrigo Rey Rosa y Franz Galich. En el caso particular de los dos últimos, sus obras se desvían de ciertas construcciones muy presentes en el imaginario colectivo. Revisan la idea de nacionalidad, tradición y

4 Participan de este proyecto, universitarios y escritores de Centro América, Europa, Canadá, Estados Unidos y Australia. La publicación de Hacia una historia de las literaturas Centroamericanas, Tomo I es el resultado de estas discusiones. El volumen II lleva por título "Tensiones de la modernidad”.

Revista Iberoamericana, Vol. LXXX, Núm. 247, Abril-Junio 2014, 553-570
ISSN 0034-9631 (Impreso) 2154-4794 (Electrónico) 
exilio para reformularlos en íntima articulación con la relación del sujeto con la ciudad que es, habitualmente, hostil. En algunas novelas y cuentos, el tratamiento que le dan a la violencia urbana está emparentado con el thriller norteamericano, como es el caso de la narrativa de Rodrigo Rey Rosa. ${ }^{5}$ La inquietud y la zozobra, la indefinición y la hostilidad son las referencias elegidas para aludir a una ciudad caracterizada por un clima de incertidumbre. Con precisión y una notable contundencia habla en los siguientes términos de la capital de su país:

Ciudad plana, levantada en una meseta orilla por montañas y hendida por barrancos o cañadas. [...] y en sus vertientes oscuras, los arrabales llamados limonadas, los botaderos y rellenos de basura, que zopilotes hediondos sobrevuelan en parvadas [...] mientras la sangre que fluye de los mataderos se mezcla con el agua de los arroyos o albañales que corren hacia el fondo de las cañadas [...] (Piedras 9-10)

Enfatiza en aspectos ciudadanos, en particular en aquellos lugares oscuros y decadentes que toda gran ciudad alberga. La periferia urbana es el ámbito donde se hace visible la orfandad de los sujetos que fueron marginados por los proyectos estatales o que debieron abandonar su país.

En "El chef", la soledad del protagonista se potencia a partir de las referencias concisas y en gran medida estremecedoras del ámbito ciudadano neoyorkino, mostrando así otro rostro del desarraigo: "Durante tres años vivió debajo del Manhattan Bridge, en una covacha al borde del terraplén sobre el río, y solía pasar buena parte de sus noches mirando por un ventanuco la telaraña de luces del vasto y roído puente tendido sobre el East River, los faros de los automóviles que iban y venían” (Ningún lugar 13). Esta referencia podría trasladarse a ciudades centroamericanas como sucede en Ningún lugar sagrado (69-98) aunque el sitio guatemalteco más mencionado sea el Petén, alusión no casual si se tiene en cuenta que fue una de las zonas más conflictivas y donde la presencia de la guerrilla convivió con los intentos de democratización del país.

En Que me maten si..., ${ }^{7}$ notable e intensa novela, el autor traza un panorama sombrío cuando se refiere a quienes perversamente alteran la función de los refugios para niños, a la perduración de la persecución y muerte de los que indagan acerca de lo que quedó después de la firma de los Acuerdos de Paz. Así muestra una Guatemala

5 Rey Rosa señala que su obra es deudora de la de Jorge Luis Borges y de Paul Bowles.

6 En este relato se alude a una máquina gubernamental que, de acuerdo con declaraciones de Rey Rosa, fue tomada del informe "Recuperación de la Memoria Histórica" donde están documentados aspectos vinculados con la represión estatal en Guatemala.

7 En esta novela la búsqueda de información acerca del funcionamiento de los supuestos hogares para los menores da como resultado muertes y encubrimientos y la certeza de que no será posible encontrar respuestas. La escena final en la que los niños juegan junto al muelle y se arrojan felices al agua es como una cinta de Moebius (127).

Revista Iberoamericana, Vol. LXXX, Núm. 247, Abril-Junio 2014, 553-570 ISSN 0034-9631 (Impreso) ISSN 2154-4794 (Electrónico) 
que sigue siendo un país en el que "la brutalidad [...] era una fuerza impersonal que se manifestaba aquí o allá, una fuerza fuera del control de los hombres, implacable y desinteresada.” (9) Violencia exterior y violencia interior definen esta narrativa caracterizada por el uso de una retórica de la brevedad y la concisión, singularmente entrelazada por un cierto lirismo.

Franz Galich, por su parte, entiende que un mundo dominado por la televisión y el videojuego permite visualizar que el thriller es el camino más certero para marcar la violencia. Elige la Nicaragua de posguerra para dar cuenta de la complejidad del mundo centroamericano y su incisiva mirada lo lleva a expresar que "[n]adie ignora que ahora, ya alcanzada la paz, Centroamérica es una zona olvidada. Prácticamente en todos los aspectos" ("Desde el centro"). La violencia constitutiva se representa en las situaciones vividas por una generación de centroamericanos en torno a imágenes nacidas de guerras intestinas, del horror de las masacres, de violaciones, de la anulación de vínculos sociales y del modo en que la sociedad vive los resabios de la guerra. Ciertos ‘aires de familia’ vinculan “El chef” con "El ratero” de Galich, en especial porque ambos relatos despliegan historias cuya marginalidad radica no sólo en los acontecimientos que se cuentan sino en una cierta naturalización de las acciones de los protagonistas, efecto logrado por la distancia que ambos narradores marcan de los hechos y por una subterránea aceptación de la violencia.

En "El ratero" no se trata sólo del hambre que padece el protagonista, sino de dejar en claro que él "sentía necesidad de que alguien supiera mis desgracias, pues al contarlas uno siente que ya se ha quitado un peso de encima”. Una vez más la soledad se hace presente y se liga con la miseria, aunque para hacerlo se parta de un juego de interpretación: la denominación ‘ratero’ guía inicialmente al lector a pensar en un ladrón, idea rápidamente abandonada al tomar conocimiento de cuál es el verdadero sentido y significación del nombre. El autor no vacila en apelar a minuciosas descripciones que muestran los avatares del protagonista, apelando a descripciones que producen inquietud y un profundo desagrado, aunque no se busca el rechazo y sí la provocación. Rey Rosa y Galich focalizan la violencia en un espacio ciudadano donde la orfandad a la que queda sometido el hombre se entronca con niveles de miseria y abyección. ${ }^{8}$

Se pone en escena el modo en que los sueños se pierden, las utopías se diluyen y los hombres no tienen opciones cuando viven en un escenario brutalmente excluyente. La certeza de que la violencia es la única compañía diaria afecta los valores patrióticos, religiosos, políticos, culturales y familiares. Se invierte la imagen de un territorio que por mucho tiempo fue imaginado como el lugar del deseo, de la abundancia, para dar paso a otro sometido, a un área que, en términos geopolíticos y culturales, no puede

8 Esta temática continúa estando presente en relatos de escritores como Ronal Flores (1973). Cfr. "Una historia cualquiera" en El futuro no es nuestro. Nueva narrativa latinoamericana.

ISSN 0034-9631 (Impreso) 
recortarse con facilidad porque “desborda con creces su propio mar” (Benítez Rojo) y porque sus voces se extienden más allá de las fronteras delimitadas en un gesto de proyección universal y de voluntad de cancelar la colonialidad.

“LAS ILUSIONES ERAN PELIGROS, CAPACES DE CORROMPER LO POCO, DE ARRUINAR LO APENITAS”

[I]nsistiré en que desde Rubén Darío los escritores centroamericanos asumimos que nuestra tradición literaria es la de la lengua castellana, que el hecho de nacer en países pequeños y medio tarados siempre nos ha planteado el reto de romper las estrechas fronteras físicas y mentales que nos constriñen, que nuestra condición marginal o periférica despierta una sed de universalidad que nos lleva a abrevar en las más diversas corrientes, que abrirnos a las más variadas literaturas para nosotros es cuestión de vida o muerte, dado el páramo del que procedemos.

Horacio Castellanos Moya, "Tres novelas centroamericanas”

Las afirmaciones del escritor honduro-salvadoreño Horacio Castellanos Moya (1957) perfilan el tono que marcará su obra y, en especial, señalan cuáles serán las cuestiones centrales en su producción literaria. Inscripta en la "narrativa de la violencia”, su escritura se orienta a expresar la desazón de quienes ven caer las expectativas ante el fracaso de los proyectos revolucionarios y la perduración de formas autoritarias. Esta compleja situación se entronca con la historia misma de un territorio que procura un reconocimiento externo e interno.

Sed de universalidad parece ser su reclamo y para ello no vacila en partir de una dura reflexión acerca de la violencia y de la condición periférica de los países centroamericanos. A lo largo de su prolífica obra, batalla con la palabra la que, con frecuencia, es más cruel que lo narrado generando un clima de inquietud alimentado por el sentimiento de frustración que acompaña a los distintos protagonistas de las historias.

Desesperanza y ausencia de proyectos, alejamiento de los ideales, abandono de las utopías son modos de hablar de un orden social, cultural y político subvertido y cuya representación consistirá en la exposición de la decadencia, del abuso de poder, del desencanto pero también de lo inquietante y lo perverso en especial cuando se los focaliza en las relaciones privadas. Castellanos Moya señala estos aspectos a lo largo de una vasta obra que desafía las convenciones: busca decir lo que no se podría decir, lo que no estaría permitido y lo hace con un lenguaje desafiante y hasta obsceno por su propia dureza.

Revista Iberoamericana, Vol. LXXX, Núm. 247, Abril-Junio 2014, $553-570$
ISSN 0034-9631 (Impreso) 
La circunstancia de haberse criado en El Salvador le permitió conocer de modo directo una sociedad sometida a un paulatino proceso de desmembramiento, experiencia que lo lleva a sostener, tanto desde la ficción como desde las notas periodísticas o de los ensayos, que los procesos dictatoriales y la guerrilla son igualmente responsables de la vida violenta y desencantada de hombres y mujeres de la región. Si bien procura alejarse de planteos nacionalistas sosteniendo que sólo es un escritor en lengua española, los aspectos relacionados con su país, en primer lugar, y con otros centroamericanos, especialmente Guatemala, constituyen una presencia rectora en el conjunto de su obra. Son recurrencias que expresan los avatares soportados por los países caribeños que produjeron y producen inestabilidad social y política. Esto se advierte de modo especial en las novelas donde la representación de una sociedad generadora de niveles de violencia, tiene una presencia muy alta que se potencia al replicarse en las vidas privadas. El ámbito en el que se narra ese tiempo de desesperanza y de decadencia es el que algunos, como M. Aguilar Ciciliano, denominan "escenario de posguerra". Castellanos Moya construye una singular visión de esos tópicos en un corpus cuyo eje, en líneas generales, está centrado en las distintas manifestaciones de la violencia, atendiendo de modo especial a la urbana. Gran parte de su obra ficcional se ocupa de estas cuestiones. El tratamiento de este tema adquiere intensidad cuando se detiene en los aspectos más sórdidos de la vida ciudadana.

En El asco. Thomas Bernhard en San Salvador, por ejemplo, elige mostrar una sociedad caracterizada por la pérdida de aquellos proyectos que la condujeron a pensar que otro mundo era posible. A lo largo de esta celebrada novela se despliega una mirada que disecciona la sociedad, focalizándola en aspectos que son tópicos centrales para la literatura latinoamericana. Así, los conflictos identitarios se expresan en historias de hombres y mujeres que lejos de estar instalados en zonas rurales y añorar un pasado mejor, habitan una ciudad dominada por la violencia y la desesperanza. Por lo tanto se entrelazan dos conceptos caracterizadores de toda su obra y que están presentes en lo público y en lo privado.

Las historias se cuentan con un lenguaje escueto, seco que representa una violencia que se vive y se piensa como consustancial a la condición de centroamericano, en primera instancia, y latinoamericano en una perspectiva más amplia. Esta relación la expresa cuando sostiene que "mi identidad como escritor reside en mi obra; lo demás es anécdota. Me gusta pensar que soy un apátrida” (Castellanos en Menjívar). ${ }^{9}$ En consecuencia, la idea de nacionalidad que despliega en una novela como El asco muestra la inutilidad de tal categoría: "Y todavía hay despistados que llaman 'nación’ a este sitio, un sinsentido, una estupidez que daría risa si no fuera por lo grotesco: cómo pueden llamar "nación”

9 Entrevista citada.

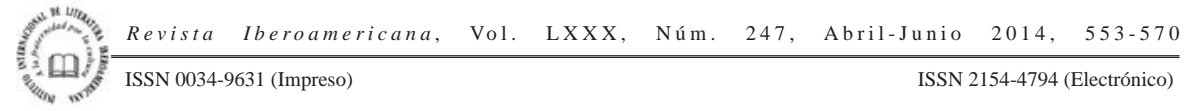


a un sitio poblado por individuos a los que no les interesa tener historia, ni saber nada de su historia [...]” (29-30).

Con una retórica semejante, Vega, el protagonista, descalifica las relaciones familiares en particular las de su hermano y su grupo familiar: "Mi hermano es un energúmeno [...] no tengo absolutamente nada que hablar con mi hermano, ni un solo tópico mínimamente decente que podamos abordar con inteligencia” (42-43). De modo semejante se refiere a la ciudad en tanto representación de toda una sociedad a la que dirige sus diatribas:

\begin{abstract}
San Salvador es horrible, y la gente que la habita, peor, es una raza podrida, la guerra trastornó todo, y si ya era espantosa antes de que yo me largara, si ya era insoportable hace dieciocho años, ahora es vomitiva, Moya, una ciudad realmente vomitiva, donde sólo pueden vivir personas realmente siniestras o estúpidas, por eso no me explico qué hacés vos aquí, cómo podés estar entre gente tan repulsiva, entre gente cuyo máximo ideal es ser sargento [...] (26)
\end{abstract}

Esta es otra de las particularidades del corpus narrativo moyano: la relevancia que tienen las ciudades en las historias. ¿Cómo se las mira? ¿Hasta qué punto esa atención no es más que la representación del modo en que se entiende y se visualiza el país? La tendencia a vincular los acontecimientos políticos con los sociales, en especial, con el campo literario, son una muestra del entrecruzamiento de lo político y lo literario. Castellanos Moya en la "Nota del autor" reafirma ese propósito: "Con fruición del resentido que se desquita, yo me había divertido durante la escritura de este libro [ $E l$ asco], en el que quise hacer una demolición cultural y política de San Salvador, al igual que Bernhard la había hecho de Salzburgo, con el placer de la diatriba y el remedo” (136), afirmaciones que confirman el alejamiento de proyectos próximos al regionalismo o la revolución y, más aún, del realismo mágico. El autor apunta a mostrar el desencanto a través de una representación desesperanzada, paródica y por momentos trágica de la nación. En esta novela, la provocación y la irreverencia se articulan para modelizar un tiempo de fracaso.

Por otra parte, el ámbito ciudadano es el lugar del caos y se presenta como un anuncio de lo que luego se depositará en el espacio privado, embebiendo los actos cotidianos y las relaciones privadas con otro nivel de violencia:

Esas casas de locos que sólo pasan viendo televisión [...] Horrible, Moya, espeluznante si la mirás de cerca: una familia que en sus ratos libres en casa no hace otra cosa que ver televisión, me dijo Vega, no existe un solo libro, mi hermano no tiene un solo libro en su casa, ni la reproducción de alguna pintura, ni siquiera un disco de música seria, nada que tenga que ver con el arte o el buen gusto puede ser encontrado en esa casa, nada que tenga que ver con el desarrollo de la inteligencia [...] (54-55)

Revista Iberoamericana, Vol. LXXX, Núm. 247, Abril-Junio 2014, $553-570$
ISSN 0034-9631 (Impreso) 
La brevedad narrativa, la palabra injuriosa, la deliberada escasez de datos y la reiteración de acontecimientos vividos por los personajes constituyen algunas de las particularidades más notables de esta novela. El lenguaje se impregna de violencia y al hacerlo dota al relato de un desorden capaz de transmitir pánico y desazón en la medida en que la palabra escueta adquiere una significación muy alta porque las referencias a la vida de los sujetos, a la cultura y a la nacionalidad carecen de registros positivos. La palabra endurece las historias porque la violencia empuja a los protagonistas a vivir al límite de sus fuerzas o sumidos en una falsa armonía. El lenguaje se desborda y la estructura de los relatos se desarticula como un modo de expresar la violencia. Se apela a una suerte de incontinencia verbal graficada en la casi eliminación de las formas tradicionales del diálogo, procedimiento que violenta, inclusive, la sintaxis:

[...] siempre me pareció la peor tontería creer que tenía algún sentido el hecho de ser salvadoreño, por eso me fui, me dijo Vega, y no me metí ni ayudé a ninguno de esos tipos que se decían mis compatriotas, yo no tenía nada que ver con ellos, yo no quería recordar nada de esta mugrosa tierra, yo me fui precisamente para no tener nada que ver con ellos, por eso los evité siempre, me parecían una peste, con sus comités de solidaridad y todas esas estupideces. (22)

Es una escritura ascética cargada de una fuerte dosis de desencanto y en la que el caos cotidiano se expresa brevemente y con una constante dosis de ironía. De allí que los mecanismos narrativos se sostengan con voces que conducen la violencia tanto hacia lo verbal como a las prácticas culturales decadentes. El asco y Baile con serpientes son una muestra de ello: "un tremendo asco me producen esos tipos tenebrosos que tienen en sus manos el futuro de este país, [...] no importa si son de derecha o de izquierdas, son igualmente vomitivos, igualmente corruptos" (32) dirá el narrador de la primera, en tanto que Sosa, protagonista de Baile con serpientes llama 'mugre’ a los vínculos familiares.

En El arma en el hombre, otra de sus novelas, la dimensión de la violencia asume matices de perversión cuando se trata de las relaciones familiares. La madre y la hermana de Robocop no vacilan en solicitarle que "despache” al padre a cambio de su libertad y, con frialdad, negocian el modo en que deberá hacerlo: “'Tendrá que ser con cuchillo', dijo mi madre, 'un arma de fuego deja mucho rastro de aquel lado’”. El nivel de perversión se desplaza de inmediato al modo en que su madre se despide: “'Cuidate, hijito’, dijo mi madre y me besó en la mejilla antes de salir” (65-66). La endeblez de los vínculos familiares violenta el mundo privado, corrompen los lazos sociales y consolidan el descreimiento en algún tipo de proyecto común. A esto debe unirse el hecho de que Robocop es otro producto -no menos perverso- del fracaso de los Acuerdos de Paz:

Convertirme en civil fue difícil. Supimos de nuestra inminente desmovilización desde que se decretó el cese de fuego. No lo creí. Las negociaciones me parecían una

\footnotetext{
Revista Iberoamericana, Vol. LXXX, Núm. 247, Abril-Junio 2014, 553-570 ISSN 0034-9631 (Impreso) ISSN 2154-4794 (Electrónico)
} 
estratagema, por lo que supiese que toda esa palabrería de los Acuerdos de Paz constituía una tregua y que en pocas semanas entraríamos nuevamente en combate, para acabar de una vez por todas con la subversión. Así se lo expliqué a mi tropa. Pero poco a poco fui comprendiendo que estaba equivocado: la guerra había terminado. (12)

El protagonista de un cuerpo de elite, el sujeto respetado por sus compañeros de batalla, el que ha recibido el nombre que lo identifica con poderes desmedidos, se queda en "el aire” porque perdió el sentido de su existencia. Sólo le quedará reconstruir su identidad y transformarse en "agente para operaciones especiales a disposición en Centroamérica” (131).

En Insensatez, el narrador procura tomar distancia de lo narrado y desligarse, así, de un rasgo fundamental del género testimonial puesto que no lo guía el propósito de otorgarle la palabra a quien no la tiene. Más bien es una voz que se sobreimprime a la colectiva. Da a conocer su interpretación de la historia narrada en íntima relación con la vivida en el presente para mostrar la pérdida de confianza en la "verdad”. La lectura de "los espeluznantes relatos" contribuye a crear un clima de tensión y angustia que se desplaza al narrador:

¡Yo soy el menos completo de la mente de todos!, pensé, con alarma, mientras me ponía de pie y empezaba a pasearme como animal enjaulado en esa oficina cuya única ventana que daba a la calle estaba tapiada para que ni los transeúntes ni quien estuviera dentro cayeran en tentación, empezaba a pasearme tal como haría con frecuencia todos y cada uno de los días que permanecí entre esas cuadro paredes [...] (16)

Las referencias a los espacios físicos son escasas pero la precisión de la adjetivación contribuye a crear un clima asfixiante. El lenguaje se impregna de violencia y al hacerlo se subvierte la sintaxis, alteración que dota al relato de un desorden capaz de revelar el poder de la palabra. Señala, además que en el país la brutalidad, la injusticia y los silencios continuarán prevaleciendo pese a que “Todos sabemos quiénes son los asesinos” (153, énfasis en el original).

Tirana memoria, por su parte, se inicia con el siguiente epígrafe de Elías Canetti:

¿No sería más correcto que no quedase nada de una vida, absolutamente nada? ¿Qué la muerte significase extinguirse de pronto en todos los que retengan alguna imagen de uno? ¿No sería más cortés frente a los que vendrán? Pues tal vez todo lo que queda de nosotros constituye una exigencia que les abruma. Quizá por eso no es libre el hombre, porque queda demasiado de los muertos en él, y ese mucho se resiste a extinguirse.

Esta referencia condensa en gran medida el proyecto narrativo de Castellanos Moya. En esta novela, el autor recurre al género diarístico como modo narrativo privilegiado, elección que tiene, desde mi perspectiva, un doble propósito: por un lado fortalece la

\footnotetext{
Revista Iberoamericana, Vol. LXXX, Núm. 247, Abril-Junio 2014, 553-570 ISSN 0034-9631 (Impreso) ISSN 2154-4794 (Electrónico)
} 
incorporación de un sujeto que, desde una subjetividad notable, cuenta una historia imbricada con el mundo privado y, por lo tanto, con lo más íntimo. Por otro, permite mostrar el lado casi frívolo de quien recurre al diario "para paliar mi soledad" (17) o “como sucedáneo a las conversaciones con mi marido” (22); junto a las nimiedades que registra, va dibujando una sociedad que vive un clima de hostilidad resultado del fuerte control del estado. Se cruzan así dos niveles distintos y hasta contradictorios: la vida de Haydée y sus observaciones ingenuas de los acontecimientos políticos y su paulatino descubrimiento del accionar de "el Brujo”.

El golpe de estado, la persecución de los rebeldes, el papel de las instituciones en tiempos de luchas intestinas se recogen en ese diario que registra los acontecimientos con liviandad e ignorancia: "El día comenzó con malos augurios: no hubo manera de que yo encontrara al coronel Palma para que me autorizara la visita a Pericles” (47) dice Haydeé para de inmediato aludir a conversaciones a la salida de la misa con gente que no tiene "la remota idea de que el golpe de Estado se iniciaría esta tarde”. El diario íntimo tiene el valor de poner en escena una voz “sometida a sus propios límites” (Morales 85).

No hay imágenes alegóricas para aludir a tiempos dictatoriales, todo está allí, en la ausencia de metáforas, en la referencia que busca ser precisa y al mismo tiempo ultrajante y en la ironía que desnuda las miserias individuales y colectivas. El lenguaje directo contribuye a presentar una situación violenta. Resulta notable el peso que el autor deposita en el lenguaje, en particular cuando se apela a una voz que por momentos marca un notorio distanciamiento frente a lo que se cuenta. Así puede leerse la incorporación de referencias a las reuniones familiares junto con alusiones al encierro de Pericles o al riesgo que corre Clemen o cuando se recurre a contar acontecimientos centrados en el débil mundo familiar. La ausencia de adjetivación, la contundencia de la historia, el ritmo de una voz que habla con nadie, que desagota ideas sin un destinatario preciso, son los rasgos más relevantes de esta novela. Resulta singular, y al mismo tiempo en estrecha relación con este recurso, el empleo del diario íntimo como género discursivo ya que quien cuenta no lo hace para compartir el relato con otro sino que esas palabras mueren en las páginas del diario y su autor confía en que nadie vaya a leerlas. Por otra parte, la intimidad del diario alberga los cambios que opera la narradora porque a medida que suceden los acontecimientos en la ciudad y en el país, se va deslizando de las confesiones más íntimas e ingenuas a otras que marcan su descubrimiento de los hechos políticos:

La pobre Rosita está fuera de sí: se pregunta una y otra vez qué es lo que ella ha hecho mal para que su hijo y su marido le paguen de esa manera, como si la culpa fuera de ellos y no del brujo. Yo he tratado de convencerla de que ambos hacen lo que les dicta su conciencia, que éste es el momento en que todos debemos arriesgar un poco para obligar a que ese hombre cruel se largue del país y nos deje en paz. (282)

\footnotetext{
Revista Iberoamericana, Vol. LXXX, Núm. 247, Abril-Junio 2014, 553-570 ISSN 0034-9631 (Impreso) ISSN 2154-4794 (Electrónico)
} 
Las desventuras revolucionarias de Clemen se narran en paralelo con el diario de Haydée; se las cuenta con cierto matiz humorístico aunque el humor constituye otra forma de señalar la inutilidad de las luchas. Las figuras de los golpistas carecen del heroísmo que pareciera reclamar este tipo de historias orientándose, en cambio, a desacralizar la participación de los activistas como Clemen:

No insistí. Pero para mí el retrato de Clemente era de trazos fuertes: del terror a la muerte pasó al alcoholismo, y para salir de ambos necesitaba una fe, que encontró en el movimiento de alcohólicos anónimos, del cual se hizo tenaz activista, terminó formando grupos de abstemios en altos círculos del poder militar y ahí se le fue la vida. (317)

Son historias que encuentran, en tiempos de posguerra, un momento histórico que muestra una visión sórdida de una sociedad vulnerable y vulnerada que vive un clima de fuerte tensión. Esta circunstancia está localizada no sólo en cuestiones políticas -como son las constantes alusiones a los golpes de estado, a los intentos revolucionarios, a la presencia de los militares-, sino también a la degradación a la que se ve sometida por el propio accionar de sus integrantes. Las imágenes se suceden reuniendo el miedo, la agresión y el desencanto:

Unos minutos después de las tres de la tarde, papá llamó a casa para decirme que los golpistas acababan de rendirse. “El brujo les minó el alma a los muy maricones”, dijo con amargura; me contó que una bandera blanca ondeaba sobre el cuartel de Primer Regimiento de Infantería. “Sólo veinticuatro horas nos duró el alegrón”, dijo. No supe desde dónde llamaba, pero se escuchaba al fondo el vocerío de los amigos, seguramente bebiendo y lamentando el desenlace de los eventos. (59)

Tampoco hay países ficcionales aunque las referencias a los lugares precisos a veces estén solapadas, como por ejemplo en Insensatez, donde a pesar de ello se reconoce a Guatemala. En el caso de Tirana memoria, al igual que en El asco, San Salvador es el sitio aludido. No hay pequeños mundos, sino que todo es uno grande e insular en el que se presentan los problemas de América Latina: caos, violencia, guerras. En esto radica el aspecto central de la narrativa de Castellanos Moya: en ese modo de plantear los acontecimientos de una sociedad que se aleja del compromiso que marcó a una generación impregnada-al igual que los proyectos revolucionarios-por el escepticismo. En el cuento "Poema de amor" que integra Con la congoja de la pasada tormenta, ${ }^{10}$ la figura del Poeta traicionado por sus propios compañeros muestra el descreimiento en los grupos guerrilleros, al tiempo que mira críticamente la participación del Poeta

10 También se publicó en Cuentos centroamericanos. Poli Délano, comp. Barcelona: Andrés Bello, 2000. 107-119.

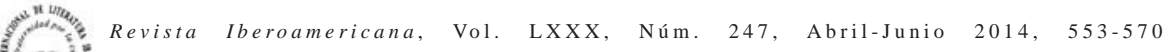
ISSN 0034-9631 (Impreso) 
-el escritor salvadoreño Roque Dalton- a quien define como "muy ingenuo, leninista utópico, preparado para enfrentar las arremetidas del enemigo, pero nunca esperó que sus propios camaradas lo asesinaran, por traidor, por llevárselas de listo, por quitarle la mujer al Choco” (181).

¿Hay posibilidad de cambio? ¿Hay alternativa para que reaparezcan los ideales que sostuvieron quienes procuraban cortar los vínculos coloniales? No se observa que los protagonistas crean en la recuperación de los proyectos revolucionarios, más bien percibe que, como dice Canetti, sería preferible que "no quedase nada de una vida, absolutamente nada”.

En el vértice de la obra moyana está la violencia porque "las ilusiones eran peligros, capaces de corromper lo poco, de arruinar lo apenitas”. Las razones por las que permeó la literatura y la sociedad están en el centro de la política y, más allá de que Castellanos Moya manifieste su descreimiento en el cruce entre política y novela, él mismo reconoce que es casi imposible no considerar el vínculo entre una y otra, especialmente porque se trata de un concepto asociado con la frustración puesto que; “el fracaso de lo político en América Latina ha formado parte constitutiva del espíritu de la época, y los buenos escritores siempre tienen una relación de amor-odio con el espíritu de su época” (“Apuntes” 12).

Castellanos Moya cartografía toda la sociedad para fraguar el desplazamiento y cambio de intereses de quienes abandonan proyectos e interpelan a un tiempo que no da suficientes respuestas. Muestra, además, -y esto es casi una constante en su obra y en la de la mayoría de los autores coetáneos al honduro-salvadoreño- la fragmentación de un territorio cuyos límites se difuminan y adquieren una notoria porosidad al permitir el ingreso de la derrota, el debilitamiento de las utopías y la dilución de la esperanza como un modo de abrir paso a una historia que, por inconclusa, se debe rearmar.

Se trata de una producción literaria particularmente generosa para abordar la desolación, la pérdida de ilusiones y la crisis de identidad cultural. Estos aspectos se imbrican con la certeza de estar asistiendo al fracaso de algunos proyectos políticos, en tanto perfilan una literatura que ingresa en una zona en la que las cuestiones privadas -caracterizadas por la derrota y hasta la ausencia de principios- no es más que la representación de una sociedad incapaz de dar respuestas a los conflictos cotidianos. En definitiva, se trata de un momento en el que tanto desde lo privado como desde lo colectivo se lo percibe como carente de utopías o anti-utópico y en el que la visión heroica de quien lucha por ideales patrióticos pierde vigencia y sentido.

\footnotetext{
Revista Iberoamericana, Vol. LXXX, Núm. 247, Abril-Junio 2014, 553-570 ISSN 0034-9631 (Impreso) 
Aguilar Ciciliano, Mauricio. "Horacio Castellanos Moya o la estética del cinismo”. 26 mayo 2003. <http://www.libros.com.sv/edicion20/horacio.html>.

Aguirre Aragón, Erick. "Control discursivo y alteridad en el testimonio centroamericano. Cinco modelos representativos”. Istmo. Revista virtual de estudios literarios y culturales centroamericanos 2 (2001). <istmo.denison.edu/n02/articulos/control. html>.

Arnulfo Agüero. "Franz Galich: la novela de la mariposa traicionera”. <www.LaPrensa. com.ni> 16 junio 2009.

Arias, Arturo.

"Descolonizando el conocimiento, reformulando la textualidad: repensando el papel de la narrativa centroamericana”. Revista de Crítica Literaria Latinoamericana XXI/42 (2do. Semestre 1995): 73-86.

Gestos ceremoniales. Narrativa centroamericana 1960-1990. Guatemala: Artemio-Edinter, 1998.

La identidad de la palabra. Narrativa guatemalteca a la luz del Siglo XX, Guatemala: Artemio \& Edinter, 1998.

Benítez Rojo, Antonio. La isla que se repite: el Caribe y la perspectiva posmoderna. Hannover: Ediciones del Norte, 1998.

Besse, Natalie. "Violencia y escritura en Insensatez de Horacio Castellanos Moya". Espéculo. Revista de estudios literarios 41 (marzo-junio 2009). <www.ucm.es/ info/especulo/numero41/insensa.html>.idad Complutense de Madrid.

Browitt, Jeffrey. "Literatura nacional y el ocaso del discurso de la nación-estado en Centroamérica". Istmo. Revista virtual de estudios literarios y culturales centroamericanos 1 (enero-junio, 2001). <http://www.wooster.edu/istmo>.

Castellanos Moya, Horacio. “Apuntes sobre lo político en la novela latinoamericana”. Cuadernos Hispanoamericanos 694 (abril 2008): 9- 17. Baile con serpientes. 1996. México: Tusquets, 2002.

Con la congoja de la pasada tormenta. Casi todos los cuentos. Buenos Aires: Tusquets, 2009. Desmoronamiento. Barcelona: Tusquets, 2006. El arma en el hombre. 2001. Buenos Aires: Tusquets, 2008. El asco. Thomas Bernhard en San Salvador. Barcelona: Tusquets, 2007. Insensatez. 2004. Buenos Aires: Tusquets, 2008. Tirana memoria. Buenos Aires: Tusquets, 2008.

Cortez, Beatriz. Estética del cinismo. Pasión y desencanto en la literatura centroamericana de posguerra. Guatemala: F\&G, 2010.

"Mapas demelancolía: La literatura como medio para la homogeneización del sujeto nacional”. Hacia una historia de las literaturas Centroamericanas. Intersecciones

\footnotetext{
Revista Iberoamericana, Vol. LXXX, Núm. 247, Abril-Junio 2014, 553-570 ISSN 0034-9631 (Impreso) ISSN 2154-4794 (Electrónico)
} 
y transgresiones: Propuestas par una historiografía literaria en Centro América. Tomo I. Werner Mackenbach, ed. Guatemala: F\&G editores, 2008. 135- 149.

Certeau, Michel de. La cultura en plural. Rogelio Paredes, trad. Buenos Aires: Nueva Visión, 2004.

Díaz Quiñones, Arcadio. Sobre los principios. Los intelectuales caribeños y la tradición. Bernal: Universidad Nacional de Quilmes, 2006.

Flores, Ronal. "Una historia cualquiera”. El futuro no es nuestro. Nueva narrativa latinoamericana. Diego trillez Paz, sel y prol. Buenos Aires: Eterna cadencia, 2009. 135-40.

Galich, Franz. "Desde el centro de la periferia de la periferia. Reflexiones de un subalterno letrado". Istmo. Revista virtual de estudios literarios y culturales centroamericanos 8 (2004). <istmo.denison.edu/n08/foro/centro.html>.

"El ratero". <http://diariodelgallo.vordpress.com/2008/04/24/3l-ratero-de-franzgalich/>. 16 dic. 2010.

"Prolegómenos para una Historia de las Literaturas Centroamericanas". Istmo. Revista virtual de estudios literarios y culturales centroamericanos 1 (enero-junio 2001). <istmo.denison.edu/n01/articulos/prolego/html>.

Liano, Dante. "Centroamérica cultural/literaria: ¿Comarca, región, zona, naciones?” Hacia una historia de las literaturas Centroamericanas. Intersecciones y transgresiones: Propuestas par una historiografía literaria en Centro América. Tomo I. Werner Mackenbach, ed. Guatemala: F\&G, 2008. 51-66.

Mackenbach, Werner. "Entre política, historia y ficción. Tendencias en la narrativa entroamericana a finales del siglo XX”. Istmo. Revista virtual de estudios literarios y culturales centroamericanos 1 (1997). <istmo.denison.edu/n15/articulo/ mackenbach.html>.

"Realidad y ficción en el testimonio centroamericano". Istmo Revista virtual de estudios literarios y culturales centroamericanos 2 (jul.-dic. 2001). <istmo.denison. edu/n02/articulos/realidad.html>.

"Representaciones del Caribe en la narrativa centroamericana contemporánea”. Reflexiones 82/2 (2002): 113-124.

Menjívar Ochoa, Rafael. "La violencia...es parte de la salvadoreñidad”. Entrevista a Horacio Castellanos Moya. El Diario de Hoy. Vértice. 16 jun. 2002. <http://www. elsalvador.com/vertice/2002/06/16/entrevista.html>. 10 abril 2009.

Morales T., Leonidas. La escritura de al lado. Géneros referenciales. Santiago de Chile: Cuarto Propio, 2001.

Ortiz Wallner, Alexandra. "Ensayar una historia cultural de Centroamérica”. Istmo Revista virtual de estudios literarios y culturales centroamericano (enero-junio 2006). <istmo.denison.edu/n12/articulos/ensayar.html>.

"Transiciones democráticas / transiciones literarias. Sobre la novela centroamericana de posguerra”. Istmo. Revista virtual de estudios literarios y

Revista Iberoamericana, Vol. LXXX, Núm. 247, Abril-Junio 2014, $553-570$
ISSN 2154-4794 (Electrónico) 
culturales centroamericanos 4 (julio-dic. 2002). <istmo.denison.edu/n04/articulos/ transciciones.html>.

Ramírez, Sergio. Balcones y volcanes y otros ensayos y trabajos. Buenos Aires: Nueva América, 1985.

Rey Rosa, Rodrigo. Ningún lugar sagrado. Buenos Aires: Alfaguara, 1998.

Piedras encantadas. Buenos Aires: el Andariego, 2001.

Que me maten si ... Barcelona: Seix Barral, 1997.

Ruiz Puga, David Nicolás. "Panorama del texto literario en Belice, de tiempos coloniales a tiempos post-coloniales”. Istmo. Revista virtual de estudios literarios y culturales centroamericanos 1 (enero-junio 2000). <istmo. denison.edu/n01/ articulos/panorama.html>.

Revista Iberoamericana, Vol. LXXX, Núm. 247, Abril-Junio 2014,
ISSN 0034-9631 (Impreso) 